\title{
Um soneto castelhano de Manuel Botelho de Oliveira
}

Anne Navarro Miranda I UNI-BH

\begin{abstract}
Resumo: Opresente artigo tem a intenção de contribuirpara a reavaliação que se vem fazendo da obra do poeta brasileiro seiscentista Manuel Botelho de Oliveira (1636-1711), em especial da parte escrita em lingua espanbola. Para tanto, constituiu-se como objeto de estudo um dos sonetos amorosos do Segundo Coro das Rimas Castelhanas, do livro Música do Parnasso dividida em quatro coros de rimas portuguesas, castelhanas, italianas \& latinas. Com seu descante cômico reduzido em duas comédias, publicado em 1705. Trata-se do segundo soneto do Coro das Rimas Castelhanas, cujo título, dado pelo autor em lingua portuguesa - tal como ocorre com os poemas escritos nas outras duas linguas estrangeiras que o poeta baiano utilizou-, é "Encarecimento da fermosura de Anarda".

Palavras-chave: Literatura brasileira; Poesia barroca; Manuel Botelho de Oliveira.
\end{abstract}

\section{Sonetos em Música do Parnasso}

soneto é a forma poética que maior grau de estabilidade apresentou ao longo da história das literaturas de línguas românicas na Península Ibérica. Karl Vossler afirma que "entre todas las formas poéticas fijas de las 
literaturas romances, es indudable que al soneto le cupo la bistoria más gloriosa." Não é essa a única nem a mais importante razão da escolha que fizemos: a opção de analisar um dos sonetos do Segundo Coro das Rimas Castelhanas da obra Música do Parnasso, de Manuel Botelho de Oliveira, deveu-se, ainda, à constatação da produtividade que essa forma encontrou ao longo da história da Literatura Brasileira e ao reconhecimento de que sua sobrevivência tornouse possível por uma enorme capacidade de adaptação a cada nova contingência literária. A plasticidade e a vitalidade da forma soneto parece justificar a idéia da existência de uma especificidade do soneto barroco ou, pelo menos, do período clássico, que compreende os séculos XVI, XVII e XVIII.

O título completo da obra - Música do Parnasso dividida em quatro coros de rimas portuguesas, castelhanas, italianas \& latinas. Com seu descante cômico reduzido em duas comédias - é revelador de que ela foi escrita em quatro idiomas. É certo que, recentemente, estudiosos elegeram, como objetos de estudo, as partes escritas em português, italiano e latim. ${ }^{3}$ Exceção feita ao trabalho de Enrique Rodrigues-Moura, não havia registro de estudo realizado sobre a parte da obra composta em espanhol. Nossa pretensão, ao escolher para análise um dos sonetos do Segundo Coro das Rimas Castelhanas - parte da obra que não vinha merecendo a atenção da crítica especializada -, é a de contribuir para a reavaliação que se vem fazendo da obra desse poeta seiscentista baiano, lançando um foco de luz sobre um poema escrito na língua de Espanha.

No Coro das Rimas Castelhanas o poeta exercitou o soneto, a canção, o madrigal, a décima e o romance. O soneto constitui a primeira forma poética empregada pelo autor nos "coros de rimas" de seu livro, em cada uma das três línguas românicas que utilizou. Apenas no Coro das Rimas Latinas não há sonetos, pois nessa parte o poeta se exercita em formas próprias da língua latina: versos descritivos de um leão, epigramas e um idílio em forma de diálogo. Além de ser a forma preferida para abrir os mencionados "coros de rimas", há

1. VOSSLER, 1960, p. 203.

2. Adotamos, neste artigo, a edição da Música do Parnasso prefaciada e organizada por Antenor Nascentes e publicada em 1953. Conservamos a ortografia dessa edição.

3. Cf. VIANNA, 2001; ALMEIDA, 1975; RIBEIRO, 1990.

4. RODRIGUES-MOURA, 2000. 
a relevância numérica do soneto em face das outras formas poéticas praticadas em língua espanhola pelo poeta. O Segundo Coro das Rimas Castelhanas - "segundo", porque o "primeiro" é o de rimas portuguesas - compõe-se, tal como ocorre com o coro que abre a obra, de duas partes: uma, com os "versos amorosos da mesma Anarda [celebrada nas rimas portuguesas]"; e a outra, com os versos vários, "escritos a vários assuntos." Em sua totalidade, o Coro das Rimas Castelhanas contém 21 sonetos (dezesseis na primeira parte e cinco na segunda), quatro canções (duas na primeira parte e duas na segunda), dezoito madrigais (todos na primeira parte), seis composições em décimas (todas na primeira parte) e 22 romances (treze na primeira parte e nove na segunda) - nessa ordem distribuídos.

Por fim, cabe assinalar a maestria com que o poeta levou a cabo a realização da forma soneto: é o que pretendemos demonstrar.

\section{Encarecimento da fermosura de Anarda}

Como é de todos sabido, consiste a forma soneto num conjunto bipartido de catorze versos, distribuídos em duas quadras e dois tercetos. Nessa configuração formal, o soneto recebe o nome de italiano. ${ }^{6}$ A cada uma dessas partes (quadras e tercetos) corresponde um conjunto fechado de rimas: no mais comum das vezes, pelo menos na Literatura Brasileira do período clássico (que equivale ao período colonial), abba/abba nas quadras; e cdc/dcd, nos tercetos. O esquema dos tercetos não é tão estável como o dos quartetos; o dado mais importante, entretanto, é que os dois conjuntos se distinguem claramente um do outro, além de outros aspectos, pela rima. O verso empregado no soneto é o hendecassílabo.

5. OLIVEIRA, 1953, tomo I, p.153-232. As páginas dos frontispícios divisórios, que separam as partes da obra, não foram levadas em conta na paginação da edição aqui utilizada.

6. Há também o soneto inglês, composto de três quadras e um dístico usualmente sem espacejamento entre as estrofes.

7. O verso hendecassílabo recebe, na nomenclatura atualmente em uso na língua portuguesa, o nome de decassílabo, porque o modo de contagem das sílabas alterou-se, em meados do século XIX, por obra de Antônio Feliciano de Castilho, em obediência à tendência, em uso na língua francesa, de contar apenas até a última sílaba tônica. No tempo de Manuel Botelho de Oliveira, e ainda hoje no sistema métrico da língua espanhola, considerava-se, para efeitos de escansão, a sílaba átona final. 
John Fuller, autor de uma pequena obra sobre a forma soneto, afirma que o soneto italiano, mais legítimo que o inglês, se caracteriza por um peculiar desequilíbrio entre suas partes. Em conseqüência dessa desigual relação entre as duas quadras e os dois tercetos, o soneto apresenta uma estrutura bipartida que corresponde, do ponto de vista formal, à necessidade conceitual de apresentarem os quartetos uma proposição, ou observação, cabendo aos tercetos expressar uma contraproposição, ou conclusão. A passagem das quadras para os tercetos, assinalada pela mudança das rimas, faz-se, no plano nocional, ou das idéias, mediante uma substituição ou torção do pensamento ou sentimento - de modo a conduzir o assunto para o desfecho por meio da surpresa ou da persuasão. Em síntese, no soneto italiano, o primeiro bloco de oito versos anuncia o tema a ser desenvolvido pelo bloco seguinte, de seis versos. Se isso se aplica ao soneto escolhido entre os do Coro das Rimas Castelhanas é o que pretendemos verificar.

Diante do universo de vinte e um sonetos do Coro das Rimas Castelhanas - dezesseis deles pertencentes aos Versos Amorosos de Anarda -, consideramos pertinente estudar um daqueles que têm Anarda por motivo -, porque nela reconhecemos o eixo temático de toda a obra Música do Parnasso.

Sobre a relevância atribuída pelo poeta aos versos de amor e, mais exatamente, à figura de Anarda, é necessário que se façam alguns esclarecimentos. O Coro de Rimas Portuguesas e o Coro das Rimas Castelhanas encontram-se ambos divididos naquelas duas partes já mencionadas: a primeira recebe o nome de Versos Amorosos de Anarda, e a segunda o de Versos Vários - estes últimos escritos, segundo diz o mesmo poeta, para que "não parecesse fastidioso o objeto", porque "assim como a natureza se preza da variedade para a fermosura das cousas criadas, assim também o entendimento a deseja, para tirar o tédio da lição dos livros." Quanto ao Coro das Rimas Italianas e ao Coro das Rimas Latinas, bem menos extensos que os dois primeiros, nota-se que não conhecem aquela divisão, apesar de que, naquele escrito em italiano, alguns poemas, claramente dedicados a Anarda, "convivem" com poemas que tratam de outros assuntos. Ora, pela ordem que as partes em que se dividem os dois primeiros coros ocupam e pela superioridade numérica dos poemas dedicados a Anarda, pode-se concluir que o poeta privilegiou os versos amorosos. A mulher a que se dedica Botelho de Oliveira, principal motivo da maior parte dos poemas do livro, representa uma convenção poética - tal como ocorreu, em exemplo mais

8. OLIVEIRA, 1953, tomo I, p. 9. 
célebre, cerca de um século mais tarde, com Marília de Dirceu. Entretanto, diversamente da personagem criada por Gonzaga, não se tem notícia da existência real de Anarda.

Em que pese a impossibilidade de averiguar-se a sua real existência, Anarda é a musa inspiradora de grande parte das composições líricas de Manuel Botelho de Oliveira: é onipresente, como indicam os títulos, no Primeiro Coro de Rimas Portuguesas em Versos Amorosos de Anarda e no Segundo Coro das Rimas Castelhanas em Versos Amorosos da mesma Anarda. À sua musa o poeta dedica também um número significativo das composições do Coro das Rimas Italianas: dois dos seis sonetos e seis dos sete madrigais, únicas formas poéticas exercitadas nessa terceira parte da Música do Parnasso, têm como motivo a figura de Anarda. Embora Manuel Botelho de Oliveira revelasse a preocupação em variar o assunto de suas rimas, Anarda está presente ainda em algumas composições dos Versos Vários pertencentes ao Primeiro Coro (no conjunto de doze oitavas intitulado "À Rosa") e ao Segundo Coro (nas canções "Descrição da Manhã" e "Descrição do Ocaso"). Anarda só não está presente no Quarto Coro das Rimas Latinas, cuja especificidade quanto ao uso de formas poéticas foi acima assinalada.

Feitos esses esclarecimentos, passemos ao exame do soneto II dos Versos de Anarda do Coro das Rimas Castelhanas. É oportuno assinalar que, nos vários coros de rimas escritos em outras línguas, os poemas trazem sempre títulos em língua portuguesa.

Encarecimento da fermosura de Anarda

Soneto II

Bello el clavel ostenta sus colores, Bella la rosa en el jardín se admira, Bello el lilio fragante olor respira, Bello el jazmín se viste de candores.

Bello el abril produce alegres flores, Bello el sol en la cuarta esfera gira, Bella la Fénix nace de su pira, Bella la luna esparce resplandores.

Mas con Anarda dulcemente hermosa No puede hallarse en todo el suelo alguna Hermosura, que brille luminosa. 
Con su belleza singular ninguna

Belleza tener pueden clavel, rosa,

Lilio, jazmín, abril, sol, Fénix, luna.

De início, chama a atenção do leitor o fato de os quartetos se destacarem nitidamente dos tercetos, o que se deve ao padrão de sua organização formal. A repetição anafórica do adjetivo "bello", com sua variação em gênero, confere aos oito versos iniciais um caráter de bloco visual e sonoramente unitário, como se fosse o adjetivo uma verdadeira coluna fixa, a partir da qual cada verso se desenvolve. Partindo desse eixo, os versos apresentam-se com estruturas sintáticas razoavelmente paralelas e autônomas - cada quarteto constituindo uma unidade sintática maior: ambos terminam por ponto-final. Além desses artifícios de composição, os quartetos apresentam-se unidos pelo esquema de rimas abba/abba, que é o esquema tradicional para essa parte do soneto.

Os oito versos desse bloco destinam-se a estabelecer elementos por comparação aos quais possa ser enaltecida a beleza inigualável de Anarda. No entanto, tal fato só se constata após a leitura de todo o soneto, já que os quartetos não realizam a promessa feita em seu título. $\mathrm{O}$ "encarecimento da fermosura de Anarda" será feito apenas nos tercetos - sob esse aspecto confirmando a teoria de Antônio Coimbra Martins, de que no soneto barroco é nos tercetos que se concentra o núcleo de seu tema. ' O papel dos quartetos, com relação à totalidade do poema, surge de sua relação com os tercetos: nos oito primeiros versos é construído um símile (termo de comparação) que, nos seis últimos, entra em correspondência com o núcleo temático do poema.

Os tercetos apresentam-se, sob diversos aspectos, em oposição às duas estrofes iniciais: no aspecto visual, quebram a coluna anafórica constituída pelo adjetivo "bello"; no aspecto sonoro, apresentam a mudança das rimas, cujo esquema passa a cdc/dcd; no aspecto sintático, exibem duas importantes alterações - a perda do paralelismo entre os versos e a perda da correspondência entre a unidade sintática e cada verso. Nessa segunda parte do soneto, cada unidade abrange a totalidade do terceto. Por fim, ainda no tocante à sintaxe, deve-se assinalar que a conjunção adversativa "mas", que dá início ao primeiro dos tercetos, implica uma mudança na linha do raciocínio até então desenvolvido, introduzindo a idéia de oposição. O tema do encarecimento da beleza de

9. Cf. MARTINS. In: COELHO, 1978. v. II, p. 1040-1043. 
Anarda aparece, portanto, nos tercetos, contrastivamente, mediante a torção do pensamento, tal como mencionado por Fuller.

\subsection{Os quartetos}

O primeiro quarteto, cujos versos referem-se a quatro flores, tem, ainda, sob outros aspectos, a sua individualidade garantida. Ele constitui o primeiro conjunto de versos hendecassílabos que apresenta o esquema de rimas abba. Do ponto de vista da sintaxe, observa-se um relativo paralelismo entre os versos cada um encerrando uma unidade sintática de estrutura semelhante à dos outros, com um sujeito e um predicado. Em todos os casos, o núcleo do sujeito recebe um mesmo adjetivo, que lhe é anteposto, e que forma aquela espécie de espinha dorsal anafórica já referida e que caracteriza ambos os quartetos.

Dos quatro versos dessa parte do soneto, três apresentam verbos de sentido ativo: o primeiro, o terceiro e o último. Esses mesmos três versos apresentam, também, acentos na sexta e décima sílabas, embora variem nos acentos secundários. E as flores a que se referem são todas designadas por palavras masculinas. Os dois versos extremos da estrofe, primeiro e quarto, que rimam entre si, apresentam, também, sem qualquer variação, o mesmo esquema rítmico: acentos na primeira, quarta, sexta e décima sílabas.

Os dois versos internos à estrofe, que também rimam entre si, distanciam-se dos outros dois não somente pela rima, mas também por um paralelismo menos acentuado - neles o predicado apresenta seus termos invertidos, com o verbo no final. Além disso, esses versos diferem dos outros dois no aspecto rítmico, mas cada um a seu modo: o terceiro verso apresenta acentuação nas sílabas primeira, terceira, sexta, oitava e décima; em comum com o verso que abre e com o que fecha a estrofe, ele apresenta o importante acento na sexta sílaba. Já o caso do segundo verso é diferente: ele é um verso especial.

O segundo verso se distingue de todos os outros, apesar de apresentar estrutura sintática semelhante. Em primeiro lugar, ele tem sentido passivo: "Bella la rosa en el jardin se admira", ou seja, no jardim a rosa se deixa admirar. Embora este verso admita leitura com o verbo na voz ativa, sendo a rosa o sujeito da oração, a análise formal do soneto confirmará a interpretação dada acima. Em segundo lugar, juntamente com o sentido passivo, incrustado num bloco de versos marcados pelo sentido ativo, o verso está marcado por outra novidade: a aparição de um elemento feminino - a rosa - em um contexto em que o elemento masculino 
prevalece - o cravo, o lírio e o jasmim. É, pois, inevitável, nesse ponto da análise, fazer corresponder a idéia de passividade à idéia de feminino. Por fim, ritmicamente, esse verso apresenta estrutura bastante diferenciada da dos demais: ele apresenta acentos na primeira, quarta, oitava e décima sílabas.

Nesse segundo verso, marcado pelas particularidades já assinaladas, devemos enfatizar que a novidade rítmica se associa a um outro dado importante: a oitava sílaba, acentuada na ausência de uma sexta acentuada, marca um lugar privilegiado no verso e na estrofe - essa oitava sílaba recai, justamente, na palavra "jardin". Ora, o jardim é o lugar onde se encontram os elementos constituintes centrais de todos os versos, que são as flores: o cravo, a rosa, o lírio e o jasmim. O termo "jardin", colocado em destaque pelo ritmo, introduz no poema, em meio aos elementos da natureza, uma dimensão cultural, pois o jardim é o lugar em que artificialmente se cultivam plantas ornamentais. No jardim não se encontram plantas e flores nascidas ao acaso; ele é o resultado da intervenção do homem sobre a natureza e tem, dessa maneira, um valor estético.

Está em Hegel a idéia de que a estética é a filosofia ou a ciência do belo, "mais precisamente do belo artístico, pois dela se exclui o belo natural." A exclusão dos fenômenos da natureza do objeto da estética é atribuída, por Hegel - comparados os dois modos de beleza -, à superioridade do belo artístico, cujas manifestações, contrariamente ao que ocorre com o belo natural, são o resultado da intervenção do espírito humano sobre a matéria. Segundo Hegel, "só é belo o que possui expressão artística, o que é criação do espírito, e que só enquanto relacionado com o espírito, ao natural se pode atribuir a beleza." Ao tomar a beleza do sol como exemplo, segundo esse ponto de vista, afirma o filósofo que sua beleza é acrescentada pelo espírito humano a algo préexistente e que ela, portanto, não tem uma existência em si mesma. O belo natural depende, pois, de que o intelecto opere sobre o objeto já existente, depende disso e a isso está subordinado: por esse motivo o belo natural participa de uma categoria inferior àquela de que participa o belo artístico. Já o belo artístico só é o que é e possui o que possui graças ao espírito.

Um jardim resulta da atividade humana sobre a natureza, buscando harmonizar, numa espécie de composição, elementos da beleza natural. À beleza acrescentada ao já existente, as flores, soma-se a beleza da composição - o

10. HEGEL, 1980, p. 79.

11. HEGEL, 1980, p. 80. 
jardim -, resultado exclusivo da atividade do espírito. A referência no soneto à beleza daquelas quatro flores do jardim, espécie de suprema beleza, constitui o primeiro termo com o qual, nos tercetos, a formosura de Anarda será posta em correlação.

A continuidade entre o primeiro e o segundo quartetos é revelada, já de início, pela rima - cujo esquema continua abba. Nessa segunda estrofe, como na primeira, a palavra "bello", por constituir elemento de repetição, funciona como pilar de sustentação de todo o conjunto de quatro versos. A posição do adjetivo, que inicia cada um dos versos dos dois quartetos, é sintomática, ainda, da intenção de unificar os substantivos a que se refere pela característica da beleza, que reúne semanticamente todos aqueles elementos e justifica o seu uso. Mais que por outras circunstâncias, as flores, na primeira estrofe, e o mês de abril, o sol, a Fênix e a lua, na segunda, estão reunidos porque são coisas belas. A beleza que os caracteriza unifica todos os elementos dos dois quartetos: ela é tomada em caráter absoluto, já que o modo indicativo empregado nos verbos enuncia a realidade pura e simplesmente, assinalando que a qualidade é real, categórica e definida, sem qualquer intervenção da subjetividade na expressão.

O segundo quarteto se distingue do anterior pelas imagens que aproxima e associa. Seu primeiro verso retoma, sob a forma genérica da categoria "flores", as imagens (cravo, rosa, lírio e jasmim) que se encontram espalhadas nos versos (e no "jardin") da primeira estrofe. Além dessa peculiaridade semântica, a palavra "flores", por estar no final do verso, é elemento importante no conjunto das rimas: por um lado, também pela evocação sonora, ela recupera os elementos do primeiro quarteto; por outro, associa-se sonora e imageticamente a "resplandores", palavra que fecha o esquema de rimas dos quartetos. Por tal mecanismo de afinidades sonoras, as flores passam a brilhar mais do que lhes é dado fazer na realidade: elas "resplendem". Ocorre, portanto, uma espécie nova de intensificação do apelo sensorial à beleza das flores. O núcleo temático do primeiro verso, expresso pela palavra "abril", indica, de um modo geral, a estação das flores. Como se vê, o poeta está mais atento às convenções poéticas do que à observação da natureza dos trópicos em que vivia.

Assim como ocorre no primeiro verso, em que a palavra "abril" é metonímia de primavera, os versos segundo e quarto desse quarteto têm como núcleo temático palavras igualmente relacionadas ao tempo em sua dimensão cósmica: o sol e a lua, respectivamente, são usados em referência às idéias de ano e mês. No terceiro verso, o tempo passa ao plano do mito: nele o núcleo temático é constituído pela Fênix, que é tomada, como assinalou Dámaso 
Alonso na poesia de Gôngora, como metáfora de "inmortalidad" e de "renovación eterna" ${ }^{12}$ - embora mencionasse também que a comparação da beleza de uma mulher com a beleza única da Fênix é algo que "ocurre con insoportable frecuencia en la poética de Góngora y de sus contemporáneos." "13

Todos os elementos que na segunda estrofe se apresentam como modelos absolutos de beleza - a primavera, designada por abril, e o sol; a Fênix e a lua -, além desse primeiro atributo comum, se reúnem, ainda, por outra razão: são todos elementos cíclicos, e dizem respeito à noção de tempo. A alusão à Fênix - ave muito longeva que para os antigos egípcios teria a capacidade de renascer de suas próprias cinzas -, no terceiro verso, introduz no poema o elemento mitológico, e, ao fazê-lo, introduz, em última análise, a presença do espírito humano. O mito é uma elaboração do pensamento que tem a finalidade de permitir a convivência do homem com a natureza a partir da compreensão dos fenômenos naturais. Segundo José Ferrater Mora, o mito é um

relato que tem dois aspectos, ambos igualmente necessários: o fictício e o real. O fictício consiste em que, de fato, não ocorreu o que o relato mítico descreve. O real consiste em que, de algum modo, o que diz o relato mítico corresponde à realidade. ${ }^{14}$

O mito é, pois, um fenômeno cultural, que onde aparece introduz um toque de humanidade. Desse modo, a presença do mito - a Fênix - entre outros elementos estritamente naturais confirma a presença humana entre os demais componentes da natureza, tanto os desta estrofe quanto os da primeira. Essa presença, que já havia sido constatada no "jardin" da primeira estrofe, aparece agora sob a forma da "Fénix". ${ }^{15}$

12. ALONSO, 1955, p. 100.

13. ALONSO, 1955, p. 98.

14. MORA, 2001, p. 478.

15. Vale ressaltar que, atualmente, a palavra "fénix" do espanhol - diferentemente do que ocorre com a palavra correspondente do português - pertence ao gênero masculino. Etimologicamente, tanto a palavra do espanhol, como a do português, deriva da forma latina feminina "phoenix". Segundo o Diccionario de Lengua Española de la Real Academia, no entanto, o substantivo "fénix", no passado, não era uniforme - foi usado também como feminino. Se era facultado escolher o gênero para a palavra "fénix", a opção por atribuir a ela o gênero feminino, no soneto em estudo, parece ter sido feita para manter o metro do verso. 
Também nesta estrofe, cada verso constitui uma unidade sintática relativamente autônoma e paralela às demais. Como ocorre no primeiro quarteto, também no segundo cada verso corresponde a uma frase com sujeito e predicado. Os versos externos apresentam, do mesmo modo, uma organização sintática muito semelhante. Os dois versos internos, que rimam entre si e com os dois versos internos da estrofe anterior, distinguem-se dos externos, cada um a seu modo. O segundo verso, neste quarteto, apresenta a particularidade de ser o único que tem o verbo no final. Como veremos, esse é um verso particularmente importante, pela correlação que contrai com o verso correspondente da primeira estrofe. O penúltimo verso tem estrutura sintática paralela à do primeiro e do quarto, e, sob esse aspecto, se distancia daquele com o qual rima (o segundo).

O segundo verso, além das particulares relações estruturais que o especificam, introduz, no sistema de imagens do poema, o sol, a idéia de "esfera", e, metonimicamente, a idéia de universo. O terceiro, que, por seu turno, se se aproxima dos outros versos do quarteto, realiza, entretanto, concretamente, o salto da natureza ao mito.

O segundo verso encerra uma alusão ao sistema geocêntrico ptolomaico. A idéia de que o sol gira na quarta esfera é reveladora de uma visão de mundo, herdada da Antigüidade Clássica e vigente no século XVII, pelo menos no campo da literatura. Segundo o sistema geocêntrico do astrônomo grego Ptolomeu (100 d.C.-170 d.C.), que dominou a astronomia até meados do século XVI, o cosmo teria a seguinte configuração:

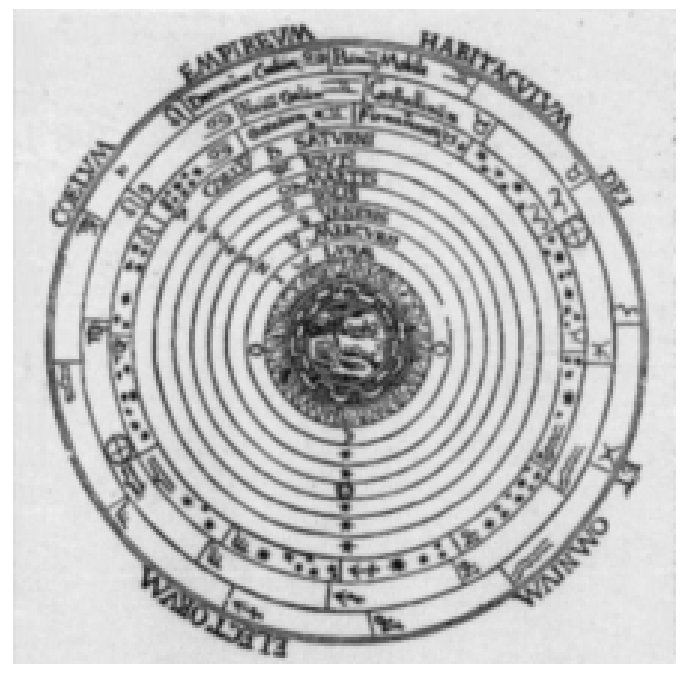

Figura - Sistema Ptolomaico. Fonte: LEÓN, 1986, p. 16. 
Conforme esse sistema, a Terra seria um globo imóvel, composto dos quatro elementos - fogo, ar, água e terra -, e ocuparia o centro do universo. As sete esferas que a circundam - a da Lua, a de Mercúrio, a de Vênus, a do Sol, a de Marte, a de Júpiter e a de Saturno - realizariam movimentos de rotação no sentido anti-horário e com durações temporais diferentes, variando de 27 dias e 1/3 a 30 anos, crescentes conforme a distância com relação ao centro. Segundo esse sistema, o Sol, astro rei, localizado na quarta esfera, levaria um ano para efetuar a volta completa ao redor da Terra. Apesar da revolução que representou a publicação do primeiro tratado de astronomia heliocêntrica, Das revoluçôes dos mundos celestes, de Copérnico (1473-1543), em que restou demonstrado o duplo movimento dos planetas - em torno de si mesmos e em torno do Sol - tem-se notícia de que em Salamanca o estudo desse então novo sistema passou a ser opcional a partir de 1561. Não era, pois, predominante, e convivia com o estudo da teoria ptolomaica. Ao que tudo indica, a aceitação das idéias de Copérnico por parte dos astrônomos não foi imediata: sua doutrina foi objeto de discussão durante todo o século XVI e só foi definitivamente adotada no século seguinte, após as descobertas de Galileu. Prova da convivência entre o sistema geocêntrico e o heliocêntrico nas academias científicas é o fato de o matemático português Pedro Nunes (1492-1577), professor de universidade, grande autoridade na ciência astronômica e cosmógrafo de el-rei D. João III, apesar de conhecer a teoria de Copérnico, haver continuado adepto da de Ptolomeu. Desse modo, pode-se constatar que o sistema heliocêntrico teve uma aceitação tardia por parte dos estudiosos da época, sendo fácil conjecturar que o sistema geocêntrico, na literatura, não foi prontamente abandonado. De fato, segundo Luciano Pereira da Silva, em sua obra A Astronomia de Os Lusíadas, Camões "tinha um conhecimento claro e seguro dos princípios fundamentais da astronomia, como ela se professava no seu tempo." ${ }^{16}$ Não obstante, não utilizou em sua obra o sistema de Copérnico. Pode-se supor que, se no mundo científico a visão de mundo havia sofrido uma completa revolução, embora convivessem as duas teorias, tal evento não afetou a visão de mundo que os poetas professavam. $\mathrm{Na}$ literatura daquela época e da época imediatamente posterior pode-se constatar a vigência de uma "tradição ptolomaica". Essa visão de mundo já ultrapassada pela ciência e em pleno uso no âmbito literário parece se inserir no contexto das convenções poéticas próprias da época.

16. SILVA, 1972, p. 2. 
Quanto ao ritmo, os versos do segundo quarteto apresentam-se da seguinte maneira: o primeiro deles, com acentos na primeira, quarta, sexta, oitava e décima sílabas; o segundo, na primeira, terceira, sexta, oitava e décima; o terceiro, na primeira, quarta, sexta e décima; e o último, na primeira, quarta, sexta e décima. O que chama atenção é o fato de todos os versos apresentarem acentos na sexta e na décima silabas. O único verso que apresenta variação significativa, se comparado aos demais, é novamente o segundo, fato que o põe em correlação com o verso correspondente do quarteto anterior. Neste caso, porém, a peculiaridade do segundo verso advém do fato de ele ser o único a apresentar tonicidade na terceira sílaba recaindo esse acento sobre a palavra "sol", núcleo temático do verso. Nos demais versos, o acento tônico que cai na quarta sílaba marca, também, pela incidência neles do tempo forte do ritmo, os núcleos temáticos: "abril", "Fénix", "Iuna".

No segundo verso, o acento na oitava sílaba recai na palavra "esfera", como na primeira estrofe recaíra sobre a palavra "jardin". Neste caso, por meio da palavra "esfera", fica nomeada a totalidade do universo, que abriga os elementos especificados nas duas estrofes. Desse modo, os segundos versos de cada quarteto estão numa correlação: na primeira estrofe, a palavra "jardín", colocada em evidência pelo acento distintivo com relação aos demais versos daquela unidade, tem a particularidade de nomear a morada das flores mencionadas em todos os versos; na segunda estrofe, também por efeito de uma acentuação peculiar frente àquela verificada nos demais versos da estância, no segundo verso, a palavra "esfera" designa a morada de todos os elementos referidos na estrofe: "abrit", "sol", "Fénix" e "luna".

Ora, a correlação que se estabelece é, pois, a que se pode verificar entre o microcosmo - o jardim -, e o macrocosmo - a esfera, ou o universo. Assim, a passagem do primeiro quarteto para o segundo efetua uma dupla operação: a de amplificação das idéias associadas à palavra "jardim" - em jogo na primeira estrofe -, promovida pelo uso da palavra "esfera"; e a de totalização do termo de comparação que tornará possível realizar, nos tercetos, a promessa do encarecimento da formosura de Anarda.

A palavra "esfera", cuja sílaba tônica é a oitava acentuada do verso, suscita a idéia de ciclo, de um todo perfeito, e o seu uso transpõe para o plano das imagens do poema a idéia da totalidade do termo de comparação. Os círculos da estrofe, figurados nas estações do ano, no sol, na lua e no ciclo mítico do renascimento da Fênix, contribuem para que o quarteto se constitua uma totalidade "fechada". Nesses círculos fica contido o círculo menor do jardim da 
primeira estrofe. Além disso, a figura dos círculos tem por corolário a figura do centro, lugar a ser ocupado pelo núcleo temático do soneto, pela imagem da beleza a ser encarecida. Os dois quartetos cumprem, desse modo, a sua função de anunciar, de maneira periférica, o desenvolvimento lógico e imagético dos tercetos.

\subsection{Os tercetos}

A unidade dos tercetos, frente à dos quartetos, está garantida em vários aspectos: eles se lhes opõem por meio da ruptura da espinha dorsal construída a partir da repetição anafórica do adjetivo "bello"; além disso, apresentam um esquema de rimas diverso: $\mathrm{cdc} / \mathrm{dcd}$, considerado perfeito por Antônio Coimbra Martins, conforme já ficou registrado. Os tercetos se distinguem dos quartetos, pois, nos seus aspectos gráfico e sonoro.

Sobre este último aspecto, o das rimas, três considerações devem ser feitas. Em primeiro lugar, é necessário recordar que, no soneto clássico, se o esquema de rimas característico para os quartetos é abba/abba - fato que se verifica em cem por cento dos sonetos de Manuel Botelho de Oliveira -, o esquema de rimas para os tercetos é mais livre. Embora sejam mais habituais as combinações cdc/dcd e cde/cde, ocorrem também outras combinações possíveis: cdd/dcc, com duas rimas; e cde/dce, cde/dec e cde/edc, com três. ${ }^{17}$ Talvez a perfeição assinalada por Antônio Coimbra Martins no esquema cdc/dcd se deva ao fato de que ele permite realizar, em comparação com o esquema mais imediatamente concorrente e, de resto, com todos os demais, uma idéia de acabamento perfeito. Não se pode negar que esse esquema, melhor do que qualquer dos outros possíveis, realiza a idéia de simetria e, portanto, de todo acabado.

Em segundo lugar, há que se considerar que o uso desse esquema cdc/dcd, no caso de Música do Parnasso, não é exclusivo do soneto em estudo, mas é algo que se verifica na totalidade dos sonetos encontrados nos três coros em que essa forma poética comparece - o de rimas portuguesas, o das rimas castelhanas e o das rimas italianas.

Por fim, cabe destacar que, segundo Rudolf Baehr, Gôngora, o poeta que Manuel Botelho de Oliveira é acusado de imitar, preferiu, majoritariamente, usar o esquema cde/cde.

17. Cf. BAEHR, 1989, p. 386.

18. Cf. BAEHR, 1989, p. 396. 
Quanto ao ritmo, observa-se que todas as cadências rítmicas presentes nos quartetos aparecem também nos tercetos, com uma ligeira diferença. Funciona o primeiro terceto da seguinte maneira: o primeiro verso apresenta acentos na primeira, quarta, oitava e décima sílabas; o segundo verso tem acentos na segunda, quarta, sexta, oitava e décima sílabas; e o último traz acentos na terceira, sexta e décima sílabas:

Mas con Anarda dulcemente hermosa

No puede hallarse en todo el suelo alguna

Hermosura, que brille luminosa.

Já o segundo terceto é particularmente difícil de analisar sob o aspecto rítmico - pela justaposição de sílabas tônicas nos dois últimos versos. Apesar das dificuldades, pode-se propor um esquema de leitura. O primeiro verso tem o mesmo ritmo do primeiro verso da estrofe anterior; o segundo tem acentos na segunda, sexta, oitava e décima sílabas - portanto, com sístole em "clavel”; e o último traz acentos na primeira, quarta, sexta, oitava e décima sílabas - com rebaixamento da tonicidade de "sol":

Con su belleza singular ninguna

Belleza tener pueden clavel, rosa,

Lilio, jazmín, abril, sol, Fénix, luna.

Os tercetos têm, também, uma especificidade sintática: cada estrofe - e não cada verso, como nos quartetos - corresponde a uma unidade. Verificase, neles, de um modo geral, que um verso não é suficiente para conter a idéia, de tal maneira que há "transbordamento" sintático e semântico (enjambement) de um verso em outro, como ocorre na passagem do segundo verso para o terceiro, na primeira estrofe ("No puede hallarse en todo el suelo alguna / Hermosura que brille luminosa"), e em toda a segunda estrofe.

O fato de um verso necessitar de outro para que sua idéia possa ser completada confere aos tercetos um andamento mais lento que aquele verificado nos quartetos, cujos oito versos se compõem de oito orações assindeticamente coordenadas e, portanto, relativamente independentes umas das outras.

No plano nocional, cada terceto tem também sua unidade: o primeiro contém a idéia de que a beleza de Anarda brilha mais do que qualquer outra 
beleza na terra; já o segundo amplifica a idéia de que a beleza de Anarda é superior à de todas as demais coisas existentes.

Ainda com respeito à sintaxe, observa-se, no segundo verso da última estrofe, uma inversão na colocação dos termos em relação à disposição considerada natural para eles na frase. "Con su belleza singular ninguna / belleza tener pueden clavel, rosa, / lilio, jazmín, abril, sol, Fénix, luna". As duas palavras destacadas, na forma em que se encontram, situam-se no centro da unidade sintática que é o terceto. Em ordem direta, o período seria "Clavel, rosa, lilio, jazmín, abril, sol, Fénix, luna ninguna belleza pueden tener con su (de Anarda) belleza singular." A torção do período pelo hipérbato põe a locução verbal no centro do terceto, abrindo, assim, caminho para a enumeração final, que constitui a recolha dos elementos disseminados nos quartetos.

A inversão daqueles termos é mais um indício da adesão de Manuel Botelho de Oliveira às convenções poéticas de seu tempo. A esse respeito Segismundo Spina afirma que

Na colocação dos termos, a poesia cultista caracteriza-se pela subversão da norma, com deslocação da palavra para lugares inesperados da frase: são os hipérbatos e sínquises (...). ${ }^{19}$

No início dos tercetos, o uso da conjunção adversativa "mas" evidencia, neles, a ruptura da coluna anafórica que sustenta os quartetos e revela a dependência dos tercetos com relação aos oito versos iniciais, por introduzir uma oposição ao que neles foi dito. Os tercetos, de fato, dependem dos quartetos, que introduziram algo essencial ao desenvolvimento do tema do soneto. O desenvolvimento da idéia da beleza de Anarda depende das imagens apresentadas nas duas primeiras estrofes: a beleza da musa supera todas as demais belezas - e essa idéia fecha-se, pelo procedimento da recolha, no final do segundo terceto.

Ainda com relação ao conectivo "mas", que introduz a segunda parte do poema, pode-se afirmar que ele realiza aquele desvio de pensamento assinalado por Fuller. Rompe-se a linearidade da idéia que se vinha desenvolvendo, ao mesmo tempo que fica sugerida a relativização da beleza dos elementos referidos nos quartetos. De certo modo, a conjunção marca, também, a

19. SPINA, 1990 , p. 29. 
substituição das estruturas frasais relativamente simples dos oito primeiros versos, construídos todos com orações coordenadas - em que somente são usadas formas verbais do modo indicativo -, por orações mais complexas nos seis últimos versos, entre as quais aparece uma subordinada - com o verbo no modo subjuntivo. O emprego desse modo verbal, para referir-se às belezas que existem "en todo el suelo", torna-as relativas por comparação a uma outra, maior que elas: a beleza de Anarda.

Cabe ainda à conjunção "mas" assinalar uma importante novidade, a aparição de Anarda, de modo a permitir que o tema se desenvolva nos versos seguintes e que se realize a promessa feita no título do soneto.

O primeiro terceto encerra a idéia de que o brilho de Anarda ofusca o brilho de tudo o que há sobre a face da terra. No segundo, em que está subentendida a conjunção que inicia o terceto anterior, reforça-se essa idéia - pois a beleza de Anarda é dita "singular" e são enumeradas todas as belezas às quais a dela se opõe.

Ainda com respeito à elipse da conjunção, pode-se considerá-la um dos recursos utilizados pelos poetas conceptistas. Segundo Segismundo Spina,

o estilo sentencioso dos conceptistas resulta na eliminação dos estados transitivos do sistema, tornando a frase concisa e sem vascularidade: são as "elipses". O conceito de Gracián, teórico do Conceptismo, "O bom, se breve, duas vezes bom", é um exemplo - por: "Aquilo que é bom, se se expressa com brevidade, resulta duas vezes melhor", em que o substantivo ("brevidade") e seu equivalente ("aquilo"), bem como os vasos capilares do edifício sintático (o relativo "que", a preposição "com", os verbos "é", "expressam", "resulta") são suprimidos como se fossem "asas de jarro, sem utilidade".

Chama a atenção, nos dois tercetos, o uso da preposição "con", acerca do qual devem ser feitas algumas considerações, sob pena de ficar prejudicada a compreensão do soneto. Os dicionários de língua espanhola, em sua maioria, acusam, para essa preposição, algumas acepções que se assemelham às que a preposição tem em língua portuguesa. O Diccionario de Lengua Española

20. SPINA, 1990, p. 29.

21. Diccionario de la lengua española de la Real Academia, 1992, v. I, p. 528. 
da Real Academia Espanhola aponta seis significados, dos quais citaremos três: 1 "significa el medio, modo o instrumento que sirve para hacer alguna cosa". 3 "expresa las circunstancias con que se ejecuta o sucede alguna cosa". 6 - "juntamente y en compañia". Esses valores da preposição não parecem ser suficientes para conferir inteligibilidade ao conteúdo dos tercetos. O Vox Diccionario General Ilustrado de la Lengua Española, cuja credibilidade foi afiançada por Menéndez Pidal, que lhe escreveu o prólogo, indica haver, ao lado de outros muitos, um quinto significado para a preposição - e o faz acompanhar de seu respectivo exemplo: "con": "comparación: 'su fuerza no es nada con la que profeso yo".

Aceitando-se a possibilidade de a preposição "con" estabelecer entre os elementos que une uma relação de comparação, subsumindo a idéia de "em comparação com", torna-se possível efetuar a compreensão dos tercetos. Assim, no primeiro, comparada com a doce beleza de Anarda, não pode haver sobre o solo outra formosura que brilhe luminosa: o brilho de Anarda se opõe ao brilho de qualquer coisa existente sobre a terra.

Nesse ponto, realiza o poeta um raciocínio engenhoso, opondo formosura a formosura. Manuel Botelho, com isso, faz justiça ao primeiro soneto do Segundo Coro das Rimas Castelhanas em Versos Amorosos da mesma Anarda, que é uma espécie de profissão de fé conceptista. Exemplo semelhante de raciocínio engenhoso nos dá o padre Antônio Vieira, quando opõe luz a luz. Escreveu ele:

Comumente se diz, que o maior contrário da luz são as trevas, e não é assim. O maior contrário de uma luz, é outra luz maior. As estrelas no meio das trevas luzem, e resplandecem mais; mas em aparecendo o Sol, que é luz maior, desaparecem as estrelas. ${ }^{23}$

No segundo terceto, a superioridade da beleza de Anarda já não se limita a ser resultado de uma comparação com o que haja sobre a terra: é superior também a toda a beleza que habita o universo - a primavera (abril), que retoma as flores do jardim, o sol e a lua -, e, nele, supera mesmo aquela beleza que habita o universo do espírito - a Fênix.

22. Diccionario Vox General Ilustrado de la lengua española, 1953.

23. VIEIRA, 1959, tomo IV, p. 311-312. 
Neste ponto da análise faz-se necessário recorrer às idéias de Heinrich Wölfflin, estudioso alemão que em muito contribuiu para o estudo da arte barroca. Em seu livro Conceitos fundamentais da história da arte, ele elabora alguns conceitos que, embora estejam aplicados à realidade das artes plásticas - pintura, arquitetura e escultura -, podem ser proveitosos também para os estudos literários. Wölfflin faz uma distinção entre forma fechada e forma aberta que pode interessar ao estudo da literatura, no geral, e das obras barrocas, em particular. Segundo esse estudioso, uma forma fechada é "uma representação que (...) apresenta a imagem como uma realidade limitada em si mesma, que, em todos os pontos, se volta para si mesma." Uma forma aberta, por sua vez, seria um estilo de representação que "extrapola a si mesmo em todos os sentidos e pretende parecer ilimitado, ainda que subsista uma limitação velada (...)." ${ }^{24}$ Segundo Wölfflin, o conteúdo de um quadro, quando correspondente a uma forma fechada, está submetido às limitações impostas pelos limites da tela - bordas e ângulos -, e tudo funciona como se um - o conteúdo - existisse em função do outro - os limites do quadro. É o que, segundo ele, ocorre com as obras do século XVI, por exemplo. No caso de obras pertencentes à categoria de forma aberta, o quadro não existiria apenas por si e para si, mas seria mostra de um espetáculo passageiro, do qual participaria o observador. Quadros desse tipo seriam típicos do século XVII. No caso do soneto em estudo, pelo uso conceptista da frase concisa, o observador - ou leitor - é chamado a participar, e sua contribuição é condição para que o sentido se constitua.

A leitura e a compreensão de um texto literário sempre exige do leitor esforço e participação. A poética barroca, de maneira geral, e a de Manuel Botelho de Oliveira, particularmente, exigem do leitor um esforço e uma participação ainda maiores. Tal exigência era reconhecida pelos próprios autores: "Não fiz livro em muitas horas para se ler em uma hora", escreveu D. Francisco Manuel de Melo, poeta contemporâneo de Botelho de Oliveira, sobre uma de suas obras. A compreensão do soneto "Encarecimento da Fermosura de Anarda", por exemplo, exige que o leitor realize algumas operações, tornadas inevitáveis pelo desenvolvimento das idéias, e, por esse motivo, o soneto pode ser incluído na categoria das formas abertas, conforme as idéias de Wölfflin. A comparação entre a beleza dos elementos naturais e cósmicos, por um lado, e a beleza de

24. WÖLFFLIN, 2000, p. 168.

25. MELO apud SPINA, 1988, p.18. 
Anarda, por outro, não é explícita no soneto, mas é por ele sugerida. O leitor é chamado à participação ativa, principalmente, no estabelecimento da relação de oposição, expressa pela preposição "con", entre a beleza de Anarda e as outras. Cabe ao leitor, enfim, concluir que a beleza de Anarda não tem, na verdade, nada que se lhe compare.

Resumen: El presente artículo tiene la intención de contribuir para la revalorización que la crítica literaria brasilera ha realizado últimamente de la obra del poeta seiscentista Manuel Botelho de Oliveira (1636-1711), especialmente en lo que respecta a aquella parte escrita en lengua española. Para ello se constituyó, como objeto de estudio, uno de los sonetos amorosos del Segundo Coro das Rimas Castelhanas, del libro Música do Parnasso dividida em quatro coros de rimas portuguesas, castelhanas, italianas \& latinas. Com seu descante cômico reduzido em duas comédias, publicado en 1705. Se trata del segundo soneto del Coro das Rimas Castelhanas, cuyo título, dado por su autor en lengua portuguesa - tal como sucede con los poemas escritos en las otras dos lenguas extranjeras que el poeta baiano utilizó-, es "Encarecimento da fermosura de Anarda".

Palabras claves: Literatura brasilera; Poesía barrueca; Manuel Botelho de Oliveira.

\section{Referências Bibliográficas}

ALMEIDA, Carmelina M. Rodrigues. O marinismo de Botelho. Salvador, Universidade Federal da Bahia, 1975. (Tese apresentada ao Instituto de Letras da Universidade Federal da Bahia para concurso de Professor Assistente do Departamento de Letras Românicas.)

ALONSO, Dámaso. Estudios y ensayos gongorinos. Madrid: Gredos, 1955.

BAEHR, Rudolf. Manual de versificación española. Madrid: Gredos, 1989.

Diccionario de la lengua española de la Real Academia. Madrid: Espasa-Calpe, 1992.

Diccionario Vox General Ilustrado de la lengua española. Barcelona: Publicaciones y Ediciones SPES, 1953.

HEGEL, Georg Wilhelm Friedrich. A concepção objetiva da arte. In. Estética: a Idéia e o Ideal. São Paulo: Abril Cultural, 1980.

LEÓN, Fray Luis de. Poesía. Prólogo y anotaciones de German Bleiberg y Dario Fernández Morera. Madrid: Alianza Editorial, 1986.

MARTINS, Antônio Coimbra. Soneto. In: COELHO, Jacinto do Prado (Dir.). Dicionário das literaturas portuguesa, brasileira e galega. 3. ed. Porto: Figueirinhas, 1978. v. II, p. $1040-1043$. 
Disponivel em: http://www.letras.ufmg.br/poslit

MORA, José Ferrater. Dicionário de Filosofia. São Paulo: Martins Fontes, 2001.

OLIVEIRA, Manuel Botelho de. Música do Parnasso dividida em quatro coros de rimas portuguesas, castelhanas, italianas \& latinas. Com seu descante cômico reduzido em duas comédias. In: NASCENTES, Antenor (Org.). Rio de Janeiro: Instituto Nacional do Livro, 1953, tomo I.

RIBEIRO, João Roberto Inácio. Música do Parnasso e a poesia latina de Manuel Botelho de Oliveira. 1990. Dissertação (Mestrado) - Faculdade de Ciências e Letras da UEP, Assis, São Paulo.

RODRIGUES-MOURA, Enrique. Manuel Botelho de Oliveira (1636-1711): um poeta, dos continentes, cuatro idiomas. Texto lido no $50^{\circ}$ Congresso Internacional de Americanistas, em julho de 2000, Varsóvia.

SILVA, Luciano Pereira da. A astronomia de 'Os Lusiadas'. Lisboa: Junta de Investigação de Ultramar, 1972.

SPINA, Segismundo. Introdução. In: MELO, D. Francisco Manuel de. A tuba de Calíope (Quarta musa das Obras métricas). São Paulo: Brasiliense, 1988. p.15-21.

SPINA, Segismundo. Maneirismo. In: SPINA e CROLL, Morris W. Introdução ao maneirismo e à prosa barroca. São Paulo: Ática, 1990, p. 9-38.

VIANNA, Marlene Machado Zica. Música do Parnasso: temas, formas, linguagem. 2001, 2 vol. (Tese de doutorado em Literatura Comparada - Faculdade de Letras, Universidade Federal de Minas Gerais, Belo Horizonte.)

VIEIRA, Padre Antônio. Sermão do Mandato (1643). In: Obras completas. Tomo IV. Porto: Lello \& Irmão Editores, 1959, p. 287-322.

VOSSLER, Karl. Formas Poéticas de los pueblos románicos. Buenos Aires: Losada, 1960.

WÖLFFLIN, Heinrich. Forma Aberta e forma fechada. In: Conceitos fundamentais da arte: o problema da evolução dos estilos na arte mais recente. São Paulo: Martins Fontes, 2000, p. 267-209. 